\title{
Online Consultation for Academic Assistance: Antidote for Distance Learning Complexity
}

\author{
Elymar A. Pascual, Rodilyn Alvarez \\ elymarpascual@rocketmail.com \\ Department of Education, Nagcarlan District, Laguna, Philippines, 4002
}

\begin{abstract}
Online consultation this time of pandemic is important for the teachers' awareness of the needs and interests of the learners in a particular subject. This study explored on the effectiveness of having online consultation in modular distance learning leading to learners' better output and academic performance. There was a weekly online consultation held for Practical Research learners through Google Meet application. This online intervention was deemed to enrich teaching and learning by having weekly consultation to learners who have specific needs in addressing the competency provided every week. The class officers of GAS and ABM were given task to collect questions for the week and facilitate in soliciting answers from the teacher during the event. This meeting was scheduled and was reflected in the Weekly Home Learning Plan distributed to learners in a regular basis. The study made use of explanatory sequential mixed method of quantitative and qualitative approaches. The participants were 51 grade 12 General Academic Strand (GAS) and Accountancy, Business and Management Learners (ABM) learners, while the respondents among the participants were 34. Findings revealed that there is a significant increase in the academic performance of Grade 12 learners in Practical Research 2 when weekly online consultation is implemented. Learners rated the different aspects of online consultation (facility in understanding, cost, timeframe and schedule, quality of output, and accommodation of teacher) as very highly satisfactory. The theme developed was focused on learners gaining knowledge: The implementation of weekly online consultation can help the students in learning as they ask questions to the teacher, producing a very good output. Reflection and challenge on building connections for better knowledge dissemination in this time of pandemic was laid down at the end of the study.
\end{abstract}

Keywords: consultation; distance; learning; online; high school

\section{Context and Rationale}

At a time when schools are closed due to COVID-19, many parents are juggling work, finances, child care and distance learning. It's a lot to manage. Although technology evolution now allows many things we haven't believed possible, the shift to e-learning doesn't go as smoothly as we want it to be. Online consultation is one of advancement of communication technology especially that we are in the pandemic. It conducts consulting service electronically in various texts such as online medical consultation and online financial service consultation. It enables participants communicate in synchronous and asynchronous way. However one of the biggest challenges facing students in general is the abrupt transition to online learning. Using technology to teach and support students with disabilities is not new to special education teachers, however, the recent abrupt transition to distance learning goes far outside the typical use of technology, as teachers are not physically able to support and engage students with the technology. To help students adjust, it is recommended that teachers should use the same software and routines that their students are familiar with as much as possible. An important benefit for students with special needs is that through collaborative consultation multiple people are getting together to communicate and share knowledge about these students, 
which results in the students being addressed according to academic need instead of special education label. Allocating an extra time and responsiveness to students beyond classroom hour are two of the qualities a great teacher embodies. The presence of a mentor to lend a helping hand no matter how small or big the scale is, is sealed to them by virtue of their profession. Thus, scheduling consultation hour is deemed necessary. It is a value-added service beyond classrooms hour for the students to seek assistance on academic, curricular and extra-curricular related concerns. The aim of consultation is to help students cope with lessons, intensify learning and complete the needed task beyond classroom hours or as simple as sharing to their teachers what bothers them. A sudden changed in behavior, a more engaged students on his academics, motivated individuals and increase score to test and quizzes are examples of desirable outcomes teachers expect among students to measure effectiveness of this program. These outcomes could be used to determine which lessons need to be strengthened as part of an intervention program plan to low performing students. The exact reason why schools and universities are implementing it is that it is academic service and in compliance with the rules and regulations of different accrediting bodies. The technical feasibility of online consultation is possible because of the proliferation of software and hardware that supports it. With 82.3 million estimated number of mobile users this 2021, reveals that adapting to technology requires less skills and effort. In fact, there are schools that allow electronic communication to address students need aside from meeting them faceto-face. Certainly, in the prevalence of modern technology, process automation is deemed necessary. This study did not compare nor identify strengths and limitations of which is better with or without technology. According to findings in the study made by Wiredu (2013, March), it can be seen that the characteristics of effective system consultation needs a high level inter-personal skills with trust and rapport. Thus, consultation allows to be undertaken within a 'no-blame' culture that, in itself, promotes collaborative working by supporting an open and honest discussion -empathy of the challenges of the consultant - using the solutionfocused language and approaches to maintain the focus of the discussion, to identify a specific and measurable outcomes and to support the capacity building. According to a Compilation of Research Online Learning (2011, September), they stated that when a group of student are learning together online, they support each other's mechanism like a guiding questions that influence the students on how they interact. Although, the students may not learned so much. According to Ayo and Villanueva (2020), they found out that the online consultation must have a result of a needed assessment which is required to have an extracurricular, curricular, and academic for students to know or to prove their willingness by using the app that required on the school policies, processes, activities and events. According to Penny (2004, June 1), he identified that the most effective way to use in improving the teaching effectiveness is the consultative feedback using meta-analysis to the students.

According to Gansle (2008), he recognized that indirect service delivery through consultation that allows many more students with special needs by receiving services is more efficient compared to direct service delivery through a school psychologist that risen the challenges that they are given more time to take care of them rather than to have more time to teach them where it is the only option available. According to Dobson (2014), he stated the importance of the collaboration consultation model to the Resource Teachers: Learning and Behavior (RTLB) which is specialized to the teachers who work in regular school with the collaboration of the school management and staff, the students, parents/whanau and the Ministry of Education, Special Education (MOE:SE) that can help to facilitates the presence, participation and learning of students who experience difficulties with learning, behavior and to have a positive outcomes. According to Gresham, \& Lopez (1996), if the teachers do not realize that the consultation is beneficial, the interventions will not be implemented, cannot be successful and they will not be occurred. According to Means and Jones (2010, September), they pointed out that the educators must have to examine a rigorous research to different types of students to know the effectiveness of the online learning they dealt with. According to Bakia and Lesseter (2012, January), educational stakeholders need rigorous information regarding the effective instructional strategies and methods for improving educational productivity. Still, there is no guarantee that the online learning can be more or less cost-effective than the other alternatives. According to Ferri (2020, 
November), there is a significant pedagogical and social challenges that the students and teachers can experience especially in an emergency situations. Pedagogical challenges are having lack of necessary electronic devices, lack of digital skills, lack of structured content versus the abundance of online resources, lack of interactivity and motivation and lack of social and cognitive presence. Whereas, the social challenges are having a lack of human interaction between teachers and students, lack of physical spaces at home to receive the lessons and the lack of support by the parents that are frequently work every time. According to Means and Baki (2013, March), they found out that the online condition performed modestly better than those receiving face-to-face instruction. Face-to-face class is extremely better than blended learning with traditional face-to-face interaction and purely online, without face-to-face conditions. According to Simon (2003), he found that not all online teachers have stable and holistic professional identities and there are no possible outcomes to know if the teachers derive more enjoyment to their online teaching.

Due to pandemic internet became necessary for students and teachers. Just like the other things, using internet has its pros and cons. It may be efficient for students but it can also be a distraction to them. Also, not all teachers are technically ready when it comes to online classes.

\subsection{Action Research Questions}

The focus of this action research is finding out the effectiveness of having online consultation together with the chosen modality in distance learning in providing better output and academic performance to SHS learners, particularly in research subject.

Specifically, it seeks to answer the following questions:

- What is the mean academic performance of the Grade 11 learners in Practical Research 1 during the first quarter of SY 2020-2021?

- What is the mean academic performance of the Grade 11 learners in Practical Research 1 during the first quarter of SY 2021-2022?

- What is the mean level of perception of the SHS learners to the following factors connected to online consultation:

a. Facility to understanding of learners;

b. Cost;

c. Timeframe and schedule;

d. Quality of output; and

e. Accommodation of teacher? And

- Does online consultation significantly affect the academic performance of learners in research subject?

\section{Proposed Innovation, Intervention and Strategy}

Online consultation refers to the students to ask what they think about the topic of teaching in which they will focus on questions such as 'who are we?', 'why do we live where we do?' and 'how do we relate to each other?'. Online consultation is important for the students to know their awareness of the needs and interests of all parties involved in the consultation that facilitates the development of effective interventions. This study would explore the effectiveness of having online consultation in distance learning providing better output and academic performance. In online consultation, there will be weekly consultation through Facebook chat room or using Google Meet application. The sample of Facebook chat room and Google meet are on the next page: 


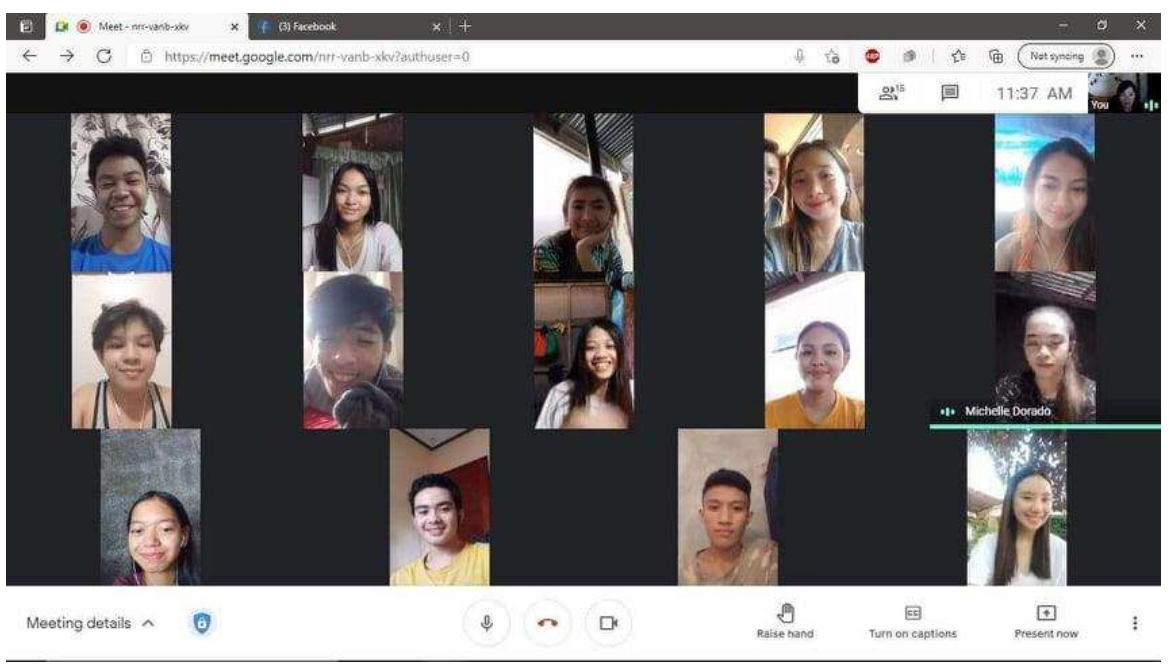

Through Facebook chat rooms, students are allowed to send their messages to one another in real time. The chat room works as a virtual room, where groups of people send messages that others can read instantaneously. At the top of your News Feed, you'll see a section called "Rooms." You can click either "Create" in the top right corner of that bar or click on the bubble with your profile picture and a plus sign to start your room. Chat room provides quality services to the students with instant response capability. Students can easily answer the questions by simply sending their messages in their chat room and can last at least 1 hour. Google Meet, also known as Google Hangouts Meet, is built to let dozens of people join the same virtual meeting, and speak or share video with each other from anywhere with internet access. It gives educators face-to-face time with their students - the best alternative to teaching from a physical classroom. With Hangouts Meet, schools can maintain the flow of communications between students, parents, guardians and fellow faculty members across a secure platform. To create a video meeting or consultation, log in to your existing Google Account or sign up for free. Invite others to your online meeting or online consultation. Send a link to the students to join the online consultation. Google Meet can empower to enrich teaching and learning with advanced features like breakout rooms, live streaming, attendance tracking, Q\&A, polling and more when you sign up for the Teaching and Learning Upgrade or Education Plus. The officers of each section are given the task to collect questions for the week and he will be the one to tell it to the teacher during the consultation. To know the question and answer in online consultation, the moderator must gather the question and answer of his classmates. It will be for just an hour. It is scheduled and it is indicated in the WHLP. When it comes to use the Facebook chat room or Google Meet application, there will be an opening prayer and closing prayer which is the assigned learner will do.

\section{Action Research Methods}

An exploratory-sequential mixed approach will be employed in this study, with both quantitative and qualitative designs being applied. The exploratory sequential mixed methods design is defined by an initial qualitative data gathering and analysis phase, followed by a quantitative data collection and analysis phase, and a final phase of data integration or linking from the two independent strands of data.

\subsection{Participants and/or other Sources of Data and Information}

Action research creates knowledge based on enquiries conducted within specific and often practical contexts. As articulated earlier, the purpose of action research is to learn through action that then leads on to 
personal or professional development. The study will make use of an explanatory-sequential mixed method, in which both quantitative and qualitative design will be used. A. Participants and/ or other Sources of Data and Information With overall 48 respondents which is the learners of Grade 12 sections ABM and GAS with the participations of their parents or guardians. The interview for online consultation action research is learners' and parents' response to the Google form. The respondents will be invited to participate through a Google form that we will provide to them. The Google form contains sentences that they need to rate from 1 5. Also, there will be a portion to the Google form which needs an open answer - a sentence or a phrase.

Table 1. Total of male and female learners in grade 12 sections ABM and GAS

\begin{tabular}{|c|c|c|c|}
\hline SECTION & MALE & FEMALE & TOTAL \\
\hline ABM & 12 & 21 & 33 \\
\hline GAS & 12 & 6 & 18 \\
\hline OVERALL & $\mathbf{2 4}$ & $\mathbf{2 7}$ & $\mathbf{5 1}$ \\
\hline
\end{tabular}

\subsection{Data Gathering Methods}

To answer the action research questions posted at the beginning of the study, the academic performance of Practical Research 2 learners last school year 2020-2021 and this school year 2021-2022 will be gathered and encoded in two arrays or columns. This data would now then be statistically treated using ttest for independent sample means to see if there is significant difference between the two sets of data. The result of this treatment will be backed-up by an online survey of learners' and parents' perception about weekly online consultation. There are five factors to be observed and they are facility to understanding of learners, cost, time-frame and schedule, quality of output, and accommodation of teacher. Perception will be measure using a 5-point Likert-Scale system. Aside from this part of the survey, an open-ended question will be answered last, giving time for respondents to share their experience in joining online consultation.

\subsection{Data Analysis}

Statistical tools will be used to analyze learners' academic performance and perception on the use of weekly online consultation as an intervention. Also, a thematic analysis will be operated to create themes that reflect the issue being raised by this action research. T-test for independent samples will be used for checking on the significant difference between academic performance with and without the use of weekly online consultation. This too is the one fitted because there are two sent of learners for the previous and the present school year. Specifically, the tools to be used are listed below.

Action Research Question \#1 - mean and standard deviation

Action Research Question \#2 - mean and standard deviation

Action Research Question \#3 - mean, standard deviation, thematic analysis

Action Research Question \#4 - t-test for independent samples, with the formula written below

$$
t=\frac{\bar{x}_{1}-\bar{x}_{2}}{\sqrt{\frac{s_{1}^{2}}{n_{1}}+\frac{s_{2}^{2}}{n_{2}}}}
$$

\footnotetext{
$\bar{x}_{1}$ : Mean value of the first group

$\bar{x}_{2}$ : Mean value of the second group

$n_{1}$ : Size of the first group

$n_{2}$ : Size of the second group

$s_{1}$ : Standard deviation of the first group

$s_{2}:$ Standard deviation of the second group
} 


\section{Discussion of Results and Reflection}

4.1. Academic Performance of Grade 11 SHS Learners without the Aid of Online Consultation

Table 2. Academic performance in practical research 2 for first quarter of school year 2020-2021

\begin{tabular}{|c|c|c|c|c|}
\hline Academic Standing & Frequency & Percentage & Mean & SD \\
\hline Outstanding (90-100) & 5 & 12.20 & 94.20 & 1.48 \\
\hline Very Satisfactory (85-89) & 16 & 39.02 & 87.19 & 1.52 \\
\hline Satisfactory (80-84) & 11 & 26.83 & 82.36 & 1.43 \\
\hline Fairly Satisfactory (75-79) & 7 & 17.07 & 77.14 & \\
\hline Failed (below 75) & 2 & 4.88 & 73.50 & 0.71 \\
\hline Overall & $\mathbf{4 1}$ & $\mathbf{1 0 0}$ & $\mathbf{8 4 . 3 7}$ & \\
\hline
\end{tabular}

The table above shows the academic performance of Grade 11 learners during the first quarter of school year 2020-2021, when weekly online consultation is not yet implemented. It can be seen that out of 41 learners taking Practical Research 2, the greatest percentage in academic performance can be seen under the category very satisfactory, which comprises grades from 85 to 89 . The least percentage on the other hand goes to the learners with academic performance which is failed (grades which are below 75). With regards to the range which is 90 and to 100, this is the decision of the Department of Education to stretch the range because of the fact that adjustment has to be made during this time of pandemic in which both mental and psychosocial state of learners are affected. Those who attain 90 and above are already considered under Outstanding to acknowledge their effort and encourage them to keep going despite pandemic. The overall mean of the 41 learners taking Practical Research 2 is 84.37 , interpreted as satisfactory, based from the range of scores. The standard deviations which are mostly greater than 1 signify heterogeneity of learners coming from two different strands - the General Academic Strand (GAS) and Accountancy Business and Management (ABM).

\subsection{Academic Performance of Grade 11 SHS Learners with the Aid Online Consultation}

Table 3. Academic performance in Practical Research 2 for first quarter of school year 2021-2022

\begin{tabular}{|c|c|c|c|c|}
\hline Academic Standing & Frequency & Percentage & Mean & SD \\
\hline Outstanding (90-100) & 22 & 43.14 & 93.75 & 86.32 \\
\hline Very Satisfactory (85-89) & 11 & 21.57 & 82.21 & \\
\hline Satisfactory (80-84) & 12 & 23.53 & 75.00 & 0.69 \\
\hline Fairly Satisfactory (75-79) & 6 & 11.76 & N/A & 0.55 \\
\hline Failed (below 75) & 0 & 0.00 & $\mathbf{8 7 . 2 3}$ & N/A \\
\hline Overall & $\mathbf{5 1}$ & $\mathbf{1 0 0 . 0 0}$ & $\mathbf{6 . 9 3}$ \\
\hline
\end{tabular}

The table above shows the academic performance of Grade 11 learners during the first quarter of school year 2021-2022, when weekly online consultation is already being implemented. There is considerably an increase of enrolment from last school year's 41 to this school year's 51, which is equivalent to $24.39 \%$ increase. This can be attributed to the fact that many grade 11 completers who were formerly from other public school transferred to Talangan Integrated National High School. Another factor that might have caused the increase is the coming of returning students who stopped studying and decided to continue this school year. It can be seen that out of 51 who are taking Practical Research 2, the greatest percentage of learners' academic performance can be seen under the category outstanding, which comprises grades from 90 to 100. The change of greatest percentage from very satisfactory of last school year to outstanding this school year is noticeable. The least percentage on the other hand goes to the learners with academic performance which is failed (grades which are below 75). The overall mean of the 51 learners coming who are taking Practical Research 2 is 87.23, interpreted as very satisfactory, based from the range of scores. The increased from last school year to this school year's overall mean is once again noticeable. The standard deviations of the category group satisfactory and fairly satisfactory are good signs that these learners are having commonality 
or their grades are near each other. For other standard deviations which are greater than 1, they signify heterogeneity of learners coming from two different strands - the General Academic Strand (GAS) and Accountancy, Business and Management (ABM).

\subsection{Facility in Understanding}

Table 4. Perception of SHS learners to online consultation in terms of facility in understanding The weekly online consultation...

1. aids in delivering the needed competency.

2. simplifies the topic by avoiding highly technical words.

3. provides explanation in producing the different parts of the study.

4. has question and answer portion that challenges students' thinking.

5. caters to both slow- and fast-paced learners.

Average

Legend: $4.21-5.00$ Very Highly Satisfactory

$3.41-4.20$ Highly Satisfactory

$2.61-3.40$ Satisfactory

$1.81-2.60$ Fairly Satisfactory

$1.00-1.80$ Unsatisfactory

The table above shows the evaluation of learners in Grade 12 (ABM) and (GAS) based on their facility in understanding in the weekly online consultation. The 34 learners satisfied that the weekly online consultation delivered aids in their needed competency, which a mean value of 4.50, standard deviation of 0.71, and an interpretation of very highly satisfactory. Simplifying the topic by avoiding technical words gained a mean value of 4.44 , SD of 0.61 , interpreted as very highly satisfactory. Provides explanation in producing different parts of the study gained a mean value of 4.59 , SD of 0.61 , interpreted as very highly satisfactory. Having a question and answer portion that challenges students' thinking gained a mean value of 4.41, SD of 0.78 , interpreted as very highly satisfactory. In caters of both slow- and fast- paced learners gained a mean value of $4.09, \mathrm{SD}$ of 0.93 , interpreted as very highly satisfactory. The overall mean value of perception of the respondents with regards to the Weekly Online Consultation to the learners is 4.41, SD of 0.73 , interpreted as very highly satisfactory. The standard deviation of mostly less than 1 implies harmony in the perception of the respondents.

\subsection{Cost}

Table 5. Perception of SHS learners to online consultation in terms of cost

\begin{tabular}{|c|c|c|c|}
\hline The weekly online consultation... & Mean & SD & Interpretation \\
\hline 1. does not require big data to access. & 4.09 & 1.03 & $\begin{array}{l}\text { Highly } \\
\text { Satisfactory }\end{array}$ \\
\hline 2. can be accessed easily as the teacher accepts the participants in the meet immediately. & 4.35 & 0.81 & $\begin{array}{l}\text { Very Highly } \\
\text { Satisfactory }\end{array}$ \\
\hline 3. can be accessed using smartphone or computer. & 4.71 & 0.52 & $\begin{array}{l}\text { Very Highly } \\
\text { Satisfactory }\end{array}$ \\
\hline 4. does not take too long for an event. & 4.29 & 0.91 & $\begin{array}{l}\text { Very Highly } \\
\text { Satisfactory }\end{array}$ \\
\hline 5. is economical instead of browsing from different sites for answers in different concerns. & 4.32 & 0.84 & $\begin{array}{l}\text { Very Highly } \\
\text { Satisfactory }\end{array}$ \\
\hline Average & 4.35 & 0.82 & $\begin{array}{l}\text { Very Highly } \\
\text { Satisfactory }\end{array}$ \\
\hline
\end{tabular}


Legend: $\quad 4.21-5.00$ Very Highly Satisfactory

$3.41-4.20$ Highly Satisfactory

$2.61-3.40$ Satisfactory

$1.81-2.60$ Fairly Satisfactory

$1.00-1.80$ Unsatisfactory

The table above shows the evaluation of learners in Grade 12 (ABM) and (GAS) based on the cost in the weekly online consultation. The 34 learners satisfied that the weekly online consultation does not required big data to access, which a mean value of 4.09, standard deviation of 1.03, and an interpretation of highly satisfactory. Can easily accessed the participants in the meet immediately by the teacher gained a mean value of 4.35 , SD of 0.81 , interpreted as very highly satisfactory. Can be easily accessed using smartphone or computer gained a mean value of 4.71 , SD of 0.52 , interpreted as very highly satisfactory. Not taking too long for an event gained a mean value of 4.29 , SD of 0.91 , interpreted as very highly satisfactory. Economical instead of browsing from different sites to answer the different concerns gained a mean value of 4.32, SD of 0.84 , interpreted as very highly satisfactory. The overall mean value of perception of the respondents with regards to the Weekly Online Consultation to the learners is 4.35 , SD of 0.82 , interpreted as very highly satisfactory. The standard deviation of mostly less than 1 implies harmony in the perception of the respondents.

\subsection{Time-frame and Schedule}

Table 6. Perception of SHS learners to online consultation in terms time-frame and schedule

\begin{tabular}{|c|c|c|c|}
\hline 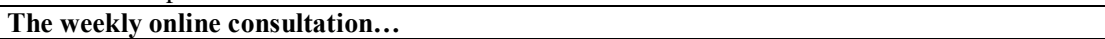 & Mean & SD & Interpretation \\
\hline 1. can be accessed at convenient time. & 4.24 & 0.85 & $\begin{array}{l}\text { Very Highly } \\
\text { Satisfactory }\end{array}$ \\
\hline 2. does not give boredom to participants. & 4.09 & 0.97 & $\begin{array}{l}\text { Highly } \\
\text { Satisfactory }\end{array}$ \\
\hline 3. provides quality time in answering concerns. & 4.53 & 0.66 & $\begin{array}{l}\text { Very Highly } \\
\text { Satisfactory }\end{array}$ \\
\hline 4. has weekly interval which is fine. & 4.32 & 0.77 & $\begin{array}{l}\text { Very Highly } \\
\text { Satisfactory }\end{array}$ \\
\hline 5. is set on proper time of day and week. & 4.44 & 0.75 & $\begin{array}{l}\text { Very Highly } \\
\text { Satisfactory }\end{array}$ \\
\hline Average & 4.32 & 0.80 & $\begin{array}{l}\text { Very Highly } \\
\text { Satisfactory }\end{array}$ \\
\hline
\end{tabular}

Legend: $\quad 4.21-5.00$ Very Highly Satisfactory

$3.41-4.20$ Highly Satisfactory

$2.61-3.40$ Satisfactory

$1.81-2.60$ Fairly Satisfactory

$1.00-1.80$ Unsatisfactory

The table above shows the evaluation of learners in Grade 12 (ABM) and (GAS) based on the timescale and schedule in the weekly online consultation. The 34 learners satisfied that the weekly online consultation can be accessed at convenient time, which a mean value of 4.24 , standard deviation of 0.85 , and an interpretation of very highly satisfactory. Does not give boredom to participants gained a mean value of 4.09 , SD of 0.97 , interpreted as highly satisfactory. In providing quality time in answering concerns gained a mean value of 4.53 , SD of 0.66 , interpreted as very highly satisfactory. Has weekly interval gained a mean value of 4.32 , SD of 0.77 , interpreted as very highly satisfactory. Set on proper time of day and week gained a mean value of 4.44 , SD of 0.75 , interpreted as very highly satisfactory. The overall mean value of perception of the respondents with regards to the Weekly Online Consultation to the learners is 4.32, SD of 0.80, interpreted as very highly satisfactory. The standard deviation of mostly less than 1 implies harmony in the perception of the respondents. 


\subsection{Quality of Output}

Table 7. Perception of SHS learners to online consultation in terms of quality of output

\begin{tabular}{|c|c|c|c|}
\hline The weekly online consultation... & Mean & SD & Interpretation \\
\hline 1. helps in producing quality output. & 4.47 & 0.71 & $\begin{array}{l}\text { Very Highly } \\
\text { Satisfactory }\end{array}$ \\
\hline 2. aids in knowing what is required in an output. & 4.47 & 0.71 & $\begin{array}{l}\text { Very Highly } \\
\text { Satisfactory }\end{array}$ \\
\hline 3. provides suggestions in having a desired output. & 4.38 & 0.70 & $\begin{array}{l}\text { Very Highly } \\
\text { Satisfactory }\end{array}$ \\
\hline 4. leads learners to continue producing output. & 4.50 & 0.66 & $\begin{array}{l}\text { Very Highly } \\
\text { Satisfactory }\end{array}$ \\
\hline 5. challenges learners in giving their best in doing their output. & 4.47 & 0.75 & $\begin{array}{l}\text { Very Highly } \\
\text { Satisfactory }\end{array}$ \\
\hline Average & 4.46 & 0.70 & $\begin{array}{l}\text { Very Highly } \\
\text { Satisfactory }\end{array}$ \\
\hline
\end{tabular}

Legend: $\quad 4.21-5.00$ Very Highly Satisfactory

$$
\begin{array}{ll}
3.41-4.20 & \text { Highly Satisfactory } \\
2.61-3.40 & \text { Satisfactory } \\
1.81-2.60 & \text { Fairly Satisfactory } \\
1.00-1.80 & \text { Unsatisfactory }
\end{array}
$$

The table above shows the evaluation of learners in Grade 12 (ABM) and (GAS) based on the quality of output in the weekly online consultation. The 34 learners satisfied that the weekly online consultation helps to have a better output, which a mean value of 4.47, standard deviation of 0.71 , and an interpretation of very highly satisfactory. Aids required in an output gained a mean value of 4.47, SD of 0.71 , interpreted as very highly satisfactory. In providing suggestions in having desired output gained a mean value of 4.38, SD of 0.70 , interpreted as very highly satisfactory. Leads to learners to continue producing their output gained a mean value of $4.50, \mathrm{SD}$ of 0.66 , interpreted as very highly satisfactory. Having a challenge to learners to do their best in doing their output gained a mean value of 4.47 , SD of 0.75 , interpreted as very highly satisfactory. The overall mean value of perception of the respondents with regards to the Weekly Online Consultation to the learners is 4.46 , SD of 0.70 , interpreted as very highly satisfactory. The standard deviation

\begin{tabular}{|c|c|c|c|}
\hline The weekly online consultation... & Mean & SD & Interpretation \\
\hline 1. is a good room for teacher-learner interaction. & 4.56 & 0.66 & $\begin{array}{l}\text { Very Highly } \\
\text { Satisfactory }\end{array}$ \\
\hline 2. has teacher-mentor that answers politely the concern of learners. & 4.53 & 0.66 & $\begin{array}{l}\text { Very Highly } \\
\text { Satisfactory }\end{array}$ \\
\hline 3. allows learners to share concern freely. & 4.59 & 0.70 & $\begin{array}{l}\text { Very Highly } \\
\text { Satisfactory }\end{array}$ \\
\hline 4. has teacher-mentor who is appreciative of learners' effort. & 4.62 & 0.60 & $\begin{array}{l}\text { Very Highly } \\
\text { Satisfactory }\end{array}$ \\
\hline 5. provides a good avenue to clarify difficult things regarding the lesson. & 4.62 & 0.65 & $\begin{array}{l}\text { Highly } \\
\text { Satisfactory }\end{array}$ \\
\hline Average & 4.58 & 0.66 & $\begin{array}{l}\text { Very Highly } \\
\text { Satisfactory }\end{array}$ \\
\hline
\end{tabular}
of mostly less than 1 implies harmony in the perception of the respondents.

\subsection{Accommodation of Teacher}

Table 8. Perception of SHS learners to online consultation in terms of accommodation of teacher

Legend: $\quad 4.21-5.00$ Very Highly Satisfactory

$3.41-4.20$ Highly Satisfactory

$2.61-3.40$ Satisfactory

$1.81-2.60$ Fairly Satisfactory

$1.00-1.80$ Unsatisfactory 
The table above shows the evaluation of learners in Grade 12 (ABM) and (GAS) based on the accommodation of teacher in the weekly online consultation. The 34 learners satisfied that the weekly online consultation is a good room for teacher- learner interaction, which a mean value of 4.56, standard deviation of 0.66 , and an interpretation of very highly satisfactory. Teacher-mentor answer politely the concern of learners gained a mean value of 4.53 , SD of 0.66 , interpreted as very highly satisfactory. Allow learners to share their concern freely gained a mean value of 4.59 , SD of 0.70 , interpreted as very highly satisfactory. Teachermentor appreciates learners' effort gained a mean value of 4.62, SD of 0.60, interpreted as very highly satisfactory. Provides a good avenue to clarify difficult things regarding the lesson gained a mean value of 4.62, SD of 0.65 , interpreted as highly satisfactory. The overall mean value of perception of the respondents with regards to the Weekly Online Consultation to the learners is 4.58, SD of 0.66, interpreted as very highly satisfactory. The standard deviation of mostly less than 1 implies harmony in the perception of the respondents.

\subsection{Effect of the Implementation of Online Consultation}

Table 9. T-test of independent samples for difference between academic performances

\begin{tabular}{|c|c|c|c|c|c|c|}
\hline Incident & Mean & SD & t-computed & t-critical & P-value & Decision \\
\hline $\begin{array}{c}\text { Without the } \\
\text { aid of QR- } \\
\begin{array}{c}\text { Coded Supp. } \\
\text { Mat. }\end{array}\end{array}$ & 84.37 & 5.77 & & & & \\
\hline $\begin{array}{c}\text { With the Aid } \\
\text { of QR-Coded } \\
\text { Supp. Mat. }\end{array}$ & 87.23 & 6.93 & -2.12 & 1.99 & & Significant \\
\hline
\end{tabular}

The table above shows the t-test result for independent samples, highlighting the significant difference of means between the two groups. The difference of the mean performance of learners in Practical Research 2 last first quarter of school year 2020-2021 (84.37)and the mean performance of learners this school year 2021-2022 (87.23) is equal to 2.86. The higher standard deviation with the implementation of weekly online consultation indicates a more varied academic performance, and it can be reasoned out by the fact that there are new students who came from other public institutions and returning students as well. The increase of 2.86 units in the academic performance is seen as significant because the absolute value of the $t$ computed (-2.12) is greater than the t-critical value (1.99). This is supported by the P-value $(0.04)$ which is less than the alpha value (0.05). With $95 \%$ level of confidence, it can be said that the implementation of weekly online consultation significantly affect the increase in academic performance.

The findings that result out of this study have similar result with the study made by Ayo and Villanueva (2020). Their claim of the effectiveness in implementing online consultation in increasing assessment score is established. When learners participate in an online consultation and raise their concerns, thereby receiving advice with regards to the needed output, academic performance is increased because the understanding or comprehension of learners is heightened. Weekly online consultation enhances learners' skill and provides them with clearer view of the topic being taught by the teacher.

\subsection{Qualitative Feedback on Insights of Learners on the Implementation of Weekly Online Consultation}

Table 10. Sample responses on the insights of learners in weekly online consultation

\begin{tabular}{|l|l|}
\hline No. & \multicolumn{1}{c|}{ Selected Responses } \\
\hline 1 & $\begin{array}{l}\text { Doing this kind of thing makes me feel happy because my questions are being answered, also in its more effective since we can } \\
\text { ask some follow up questions. }\end{array}$ \\
\hline 2 & The teachers have put a big effort on this weeks' implementation of weekly online learning. \\
\hline 3 & Online consultation helps me to give the answer on my question and understand it simply. \\
\hline
\end{tabular}




\begin{tabular}{|c|c|}
\hline 4 & $\begin{array}{l}\text { The online consultation is also very helpful and I understand the topic easier with this set-up. However, I tend to forgot that there } \\
\text { is a consultation sometimes so I suggest to remind the students on the day before or hours before the meet. }\end{array}$ \\
\hline 5 & $\begin{array}{l}\text { The consultation is very beneficial because you have a reliable source if you have questions instead of browsing in the internet } \\
\text { which you don't know if true or not. }\end{array}$ \\
\hline 6 & $\begin{array}{l}\text { It's better for the students to have an online orientation so they can free ask about the module they are having a trouble answering } \\
\text { it }\end{array}$ \\
\hline 7 & $\begin{array}{l}\text { I suggest that in weekly online learning we must explain and show proper and good examples and directions/instructions to } \\
\text { avoid of the children's confusions. }\end{array}$ \\
\hline 8 & $\begin{array}{l}\text { For me through the online consultations, we can easily finish our outputs in practical research } 2 \text { and it can help us to learn more } \\
\text { techniques to easily write a research paper even though we don't have face to face interactions. }\end{array}$ \\
\hline 9 & $\begin{array}{l}\text { Online consultation is a good way to communicate with teacher. This is formal, because it consists of questions and answers only } \\
\text { about the topic. }\end{array}$ \\
\hline 10 & My suggestion is online consultation is only at Monday because we have lots of module thanks $u$. \\
\hline 11 & The online consultation is very helpful for our studies \\
\hline 12 & $\begin{array}{l}\text { My overall feedback with regards to the implementation of weekly online learning is very good. I don't have any suggestion here } \\
\text { because the implementation is better for students utmost learning. }\end{array}$ \\
\hline 13 & $\begin{array}{l}\text { It was really a big help especially to those who feels the difficulty in using websites, it also gives an open conversation between } \\
\text { teacher and students. }\end{array}$ \\
\hline 14 & $\begin{array}{l}\text { Mas gusto ko pa pong maraming matutunan at para mas maintindihan ko ang lahat ng gagawen dahil minsan nahihirapan po ako } \\
\text {. }\end{array}$ \\
\hline 15 & The speakers always to a good speech and there speeches are loud and clear \\
\hline 16 & My overall feedback to this implementation of weekly online learning is specific to the individual learner's needs o \\
\hline 17 & The weekly online learning provides an answer to my questions that helps me in making my outputs. \\
\hline 18 & $\begin{array}{l}\text { As a student, that is currently in social distance learning kinda hard for us encourage our self to be motivated alone. So I'm } \\
\text { thankful that our teachers finding a way to reached out and help us. }\end{array}$ \\
\hline 19 & $\begin{array}{l}\text { The online consultation that we are attending every week, has an important impact on us, students. To ask our concerns freely } \\
\text { and our considerate teacher is always trying his best to answer. Allow us also to keep going/doing our output in its best and } \\
\text { accurate. }\end{array}$ \\
\hline 20 & The online learning implementation is good and gives us more information \\
\hline 21 & $\begin{array}{l}\text { It is very helpful for us because we can easily ask our concerns regarding our topics/lesson it is also entertaining because our } \\
\text { teacher answers the questions politely }\end{array}$ \\
\hline 22 & Hopefully each activity will have clearer instructions and examples so that we can understand it faster. \\
\hline 23 & it is good for us because we get an idea and ask questions properly, and gain new knowledge \\
\hline 24 & It help us to communicate with each other and assist us when we need some answer or feedback to our give question \\
\hline 25 & The online consultation was very helpful for us students and also teachers in clarifying and acquiring more knowledge. \\
\hline 26 & We need to communicate with our teachers \\
\hline 27 & the topic. This online consultation helps us to clarify things. \\
\hline
\end{tabular}

The table in the previous page shows selected, unique responses from the survey conducted, asking for qualitative response from the question, "What is your overall feedback with regards to the implementation of weekly online learning? The thirty-four participant learners were able to answer the survey. From the responses, the 2D-Word Cloud formed and the table of frequently appearing words are as follows:



Fig. 1. 2D-word cloud of frequently appearing words on insights in weekly online consultation 
Table 10. Table of frequently appearing words on insights in weekly online consultation

\begin{tabular}{|c|c|c|}
\hline No. & Word & Frequency \\
\hline 1 & questions & 8 \\
\hline 2 & learning & 8 \\
\hline 3 & can & 6 \\
\hline 4 & help & 6 \\
\hline 5 & very & 6 \\
\hline 6 & students & 6 \\
\hline 7 & good & \\
\hline
\end{tabular}

Analyzing the frequently appearing words against the raw document response, the resulting theme is thus formulated:

Theme (Learners gaining knowledge):

The implementation of weekly online consultation can help the students in learning as they ask questions to the teacher, producing a very good output.

The Implementation of Weekly Online Consultation helps the students in learning because it establishes good learning aid. Aside from having communication and collaboration of the learners to teacher, weekly online consultation gives a broader and better explanation to learners. The content Implementation of Weekly Online Consultation provided them additional understanding and learning, making clear what can be hear from the teacher's explanation and clarifications. Weekly Online Consultation increase learner's knowledge the way they ask questions to have a very good output. Asking questions through weekly online consultation gives a way to gain clarity of what learner's experience difficulties. Also, it is essential for keeping them engaged with the task at hand. The Implementation of Weekly Online Consultation of teacher in answering the learner's questions and concerns through online consultation gain a new knowledge and entertainment. This deducted time of weekly online consultation for enhancement material is thus allotted to more time in helping learners understanding the topic, probably by answering their questions and concerns through weekly online consultation wherein learners are inquiring of clarification of the lesson in practical research 2. The Weekly Online Consultation which aids in learners' understanding of the topic, thus, takes its role of explaining difficult concepts in research.

\section{Reflection}

COVID-19 has resulted in schools being shut all across the world. As a result, education has changed dramatically, with the distinctive rise of e-learning, whereby teaching is undertaken remotely and on digital platforms. However, the author of this study provides an online consultation to the students to seek their questions and difficulties in learning to be answered by the teacher. It can be seen in this study that online consultation can help the students in learning ask they ask questions to the teacher regarding to their difficulties and queries in practical research 2, producing a very good output. In online consultation, students also learned to communicate with the teacher which is really good. With online consultation, students have the opportunity to reach out their questions and concerns. Also, it explores best practice to the teacher on ways to enhance their teaching and improves student's learning. Although, online consultation has frequent scheduled which is every Monday, the students are still making their modules and responsibilities at home. Not all students are able to attend the weekly online consultation. The author realized through this study that educators have a great challenge of communicating with all the students because of the "lack of internet access" for the students. The term lack of internet access signifies the possible internet gap of the teachers and 
the learners. Students who have missed large amounts of academic assistance and information in online consultation can lead them to poor understanding in making their output good in practical research 2 because they missed the opportunity to ask questions and gain new knowledge as well. The prevailing truth is that the not all students are capable of having internet access or connection to connect with the teacher through online consultation. This is the very reason why this study was conducted - reaching out to the academic assistance to students in learning even in this time of pandemic. The teacher should never stop of making ways for knowledge to be accessible given the present scenario and considering the ways in which the students access information and ask questions in online consultation. Online consultation enables the teacher and the student to set their own learning pace, and there's the added flexibility of setting a schedule that fits everyone's agenda. As a result, using an online consultation allows for a better knowledge in doing the student's output in research, so there's no need to give anything up. The true goal of education is "to be self-aware". A mind without consciousness is nothing and knowledge and education brings consciousness. Education aware one about his/her purpose so that he/she can live the life in his/her own efficient and better way. It helps in living the life to its fullest. The students should realize they are capable of improving their efficacy, confidence, communication skills and started to exert an effort in studying. With the everyday advancement in technology, one of which is buzzing around is online consultation for academic assistance to students. One of the most important aspects of online consultation for academic assistance is flexibility. Consultation for academic assistance: antidote for distance learning complexity give an adaptable and flexible learning framework that empowers students the same to tailor their preparation to fit with their particular conditions. The teacher and students need to build a connection that gives them a better knowledge especially in this time of pandemic.

\section{References}

Ayo, E. B., Montero, D., Dote, D., and Villanueva, L. (2020). Development of Online Teachers-Student Consultation Application iJIM. Vol. 14, No. 8.https://doi.org/10.3991/ijim.v14i08.11284

Bakia, M., Shear, L., Toyama, Y. and Lasseter, A. (2012, January).Understanding the Implications of Online Learning for Educational Productivity.SRI International.U.S. Department of Education Office of Educational Technology.Center for Technology in Learning.

Dobson, E., Glifford-Bryan, J. (2014). Collaborative-Consultation: A Pathway for Transition. KAIRARANGA. Volume 15, Issue 1.

Ferri, F., Grifoni, P. and Guzzo, T. (2020, November).Online learning and emergency remote teaching: opportunities and challenges in emergency situations. [Concept Paper, Institute for Research on Population and Social Policies, National Research Council]. 00185 Rome, Italy.

Gansle, K. A., Noell, G. H. (2008). Consulting with Teachers Regarding Academic Skills: Problem Solving for Basic Skills.International Journal of Behavioral Consultation and Therapy.Volume 4, No. 2

Gresham, F. M. \& Lopez, M. F. (1996). Social validation: A unifying concept for school-based consultation research and practice. School Psychology Quarterly, 11(3), 204-227.

Means, B., Toyama, Y., Murphy, R. and Baki, M. (2013, March). The Effectiveness of Online and Blended Learning: A Meta-Analysis of the Empirical Literature. Teachers College Record.Volume 115, 030303. Columbia University 0161-4681

Means, B, Toyama, Y., Murphy, R. Baki, M. and Jones, K. (2010, September).Evaluation of Evidence-Based Practices in Online Learning: A Meta-Analysis and Review of Online Learning Studies. Center for Technology in Learning.U.S. Department of Education.Office of Planning, Evaluation and Policy Development.Policy and Program Studies Service.

Penny, A. R., Coe, R. (2004, June 1). Effecgtiveness of Consultation on Student Ratings Feedback: A Analysis.https://journals.sagepub.com/ doi/abs/10.3102/00346543074002215?j ournalCode $=$ rera

Research on the Effectiveness of Online Learning: A Compilation of Research on Online Learning. (2011, September). The Future of State Universities.

Simon, E. (2003). The impact of online teaching on higher education faculty's professional identity and the role of technology: the coming of age of the virtual teacher. [A Thesis submitted to the Faculty of the Graduate School of the University of Colorado in partial fulfillment of the requirement for the degree of Doctor of Philosopy]. ATLAS Institute.

Wiredu, M. (2013, March).An investigation into the characteristics of effective school-based consultation.[A thesis submitted to The University of Birmingham for the degree of DOCTOR OF PHILOSOPHY (EDUCATION)]. School of Education, College of Social Sciences. The University of Birmingham. 